\title{
Experimental and Analytical Performance Evaluation of SiC Power Devices in Matrix Converter
}

\author{
Saeed Safari, Alberto Castellazzi, Pat Wheeler \\ PEMC Group, University of Nottingham, Nottingham, UK, E-Mail: eexss12@ nottingham.ac.uk
}

\begin{abstract}
With the commercial availability of SiC power devices, their acceptance is expected grows in consideration to the excellent low switching loss, high temperature operation and high voltage rating capabilities of these devices. This paper presents the comparative performance evaluation of different $\mathrm{SiC}$ power devices in matrix converter at various temperatures and switching frequencies. To this end, firstly, gate or base drive circuits for Normally-off SiC JFET, SiC MOSFET and SiC BJT which taking into account the special demands for these devices are presented. Then, three 2-phase to 1-phase matrix converters are built with different SiC power devices to measure the switching waveforms and power losses for them at different temperatures and switching frequencies. Based on the measured data, three different $\mathrm{SiC}$ power devices are compared in terms of switching times, conduction and switching losses and efficiency at different temperatures and switching frequencies. Furthermore, a theoretical investigation of the power losses of three phase matrix converter with Normally-off SiC JFET, SiC MOSFET, SiC BJT and Si IGBT is described. The power losses estimation indicates that a $7 \mathrm{KW}$ matrix converter would potentially have an efficiency of approximately $96 \%$ in high switching frequency if equipped with $\mathrm{SiC}$ devices.
\end{abstract}

Keywords — Normally-off SiC JFET; SiC MOSFET; SiC BJT; power losses evaluation; matrix converter

\section{INTRODUCTION}

Recently significant effort has been made to increase the performance of the semiconductor devices utilized in power conversion circuits. Wide band gap Semiconductors such as Silicon Carbide (SiC) have demonstrated good charateristics for improving on the limitations associated with the current state of the art technology for power switching devices [1]. SiC devices can provide good performance in applications which demand high switching frequencies [1].

SiC devices can also sustain high operating temperatures, thus making them attractive candidates for aerospace applications [2] where the high temperature operation an reduce the weight and volume of the cooling system. In many applications SiC devices can help in the design of power converters with higher efficiencies due to lower switching losses compared to conventional Silicon (Si) based devices [3].. 
In recent years, some of research efforts about $\mathrm{SiC}$ power converters have concentrated on DC/DC applications which have simple topologies and less complexity [4]. In addition, some efforts have been done in developing three phase power rectifier with switching frequency of $150(\mathrm{KHz})$ [5]. Furthermore, also there is an effort to develop three phase inverter using only SiC devices. [6] presented an SiC AC/DC/AC converter which consists of a Vienna-type rectifier front end and a two-level voltage source inverter and tested at $10(\mathrm{KW})$ with $70(\mathrm{KHz})$ switching frequency. Moreover, [7] demonstrated a $100(\mathrm{KHz}), 1.5(\mathrm{KW})$ $\mathrm{SiC}$ sparse matrix converter, but $\mathrm{SiC}$ cascade devices which limit the maximum operating temperature of power converter were employed.

It is important to understand how $\mathrm{SiC}$ devices are different from the conventional Si devices and in which circuit topologies they can be used to to directly replace their Si counterparts. Therefore this paper aims to present a comprehensive comparisons of the two technologies in the device static characteristics, switching performances, temperature behaviors and loss distributions in a high frequency matrix converter. Previous works $[8,9]$ haveinvestigated performance of SiC JFET and MOSFET analytically in matrix converter topologies. $\mathrm{T}$, this paper presents the performance comparison of different SiC devices such as JFET, MOSFET and BJT and Si IGBT matrix converters switching at high switching frequencies, which therefore have smaller, more compact input filters.

\section{THE MATRIX CONVERTER}

Matrix converters as bidirectional direct power electronic converters are able to provide synchronous amplitude and frequency transformation in AC electrical system. They are employed in frequency changers and electrical drives. In compare with Back to Back converters as another kind of AC-AC power converters, there is no energy storage elements in matrix converter topology so it is called an all silicon solution in power conversion. In fact, the weight and volume of the matrix converter due to lack of DC link capacitor is decreased in compare with another kind of ac power converter which has energy storage elements [10].

One of the interested features of matrix converters is sinusoidal input and output currents. Also with suited modulation techniques, the input phase displacement factor can be adjusted then it is possible for matrix converter to achieve unity power factor in any load. They are able to generate load voltage with arbitrary amplitude and frequency, therefore operation under abnormal input voltage conditions is possible for them [10].

The matrix converter consists of an array of controlled bidirectional switches; in fact with matrix converter is possible to connect an m-phase voltage source to an n-phase load directly. Among different configurations for matrix converter, an array 
of three by three bidirectional switches is more interest in industry due to it connects a three phase source to a three phase load as shown in Fig. 1.

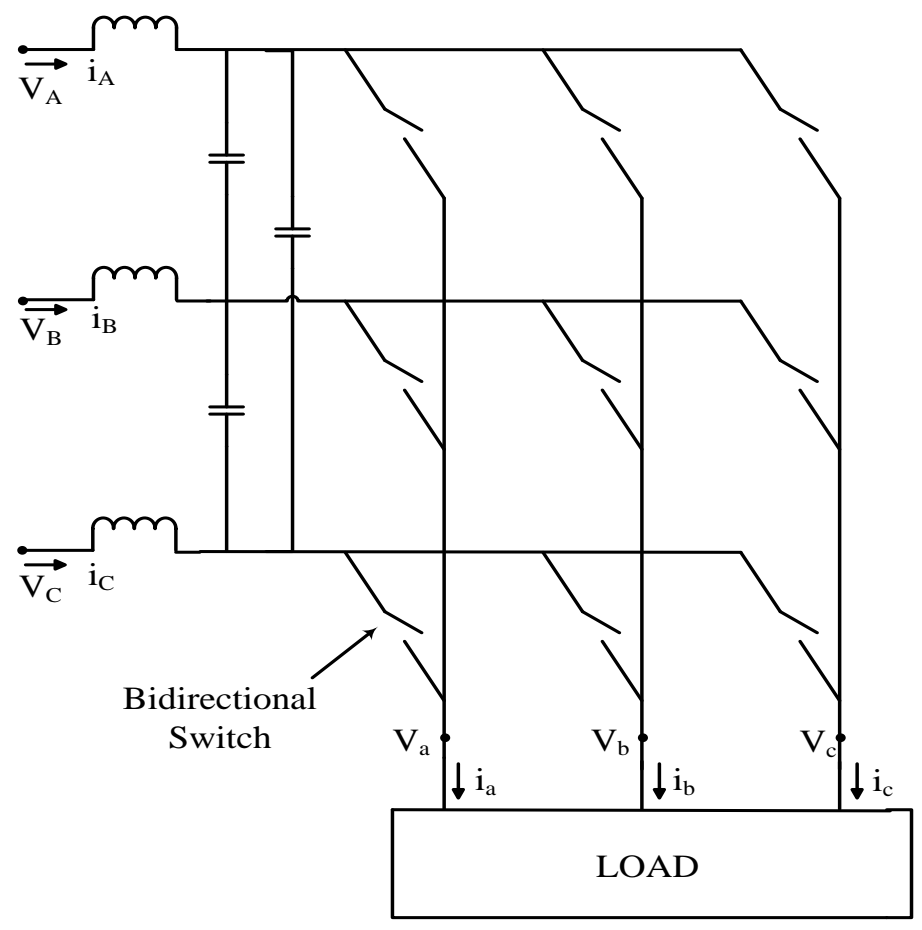

Fig. 1. The basic structure of a three phase $\mathrm{SiC}$ matrix converter

However, due to lack of energy storage element, voltage transfer ratio of matrix converter is limited to 0.866 and this is a main disadvantage of matrix converter. Also due to high number of power electronic switches, the switching loss of matrix converter is higher than other AC-AC power converters.

The EMI filter capacitor of matrix converter which is put in the input of matrix converter requires being a small value for the application of matrix converter with high input frequency (for example from 360 to $800 \mathrm{~Hz}$ ) in contrast to standard 50/60 $\mathrm{Hz}$ mains application in order to keep the reactive power low and to satisfy the power factor requirement. However, it is needed a large input capacitance to keep input voltage ripple and harmonic distortion low especially for such application with high peak output power. Thus this is not applicable because of reactive power limitation. The main solution for this problem is to raise frequency of switching but it depends on performance, efficiency, volume and weight requirements.

\section{THE SIC POWER ELECTRONIC DEVICES}

Nowadays $\mathrm{SiC}$ power electronic device is known as a high voltage and high switching frequency device in contrast with $\mathrm{Si}$ device. In fact, the $\mathrm{SiC}$ power semiconductors possess intrinsic advantages as high voltage blocking capability, low on-state 
voltage drop, high switching speed and low thermal resistance [11]. Thus the conduction and switching losses of SiC power devices could be decreased and the operating temperature could be increased in compare by Si power devices. Therefore, based on the $\mathrm{SiC}$ power devices, achieving highly compact converter systems with lower conduction and switching losses and high voltage is possible.

Moreover, due to high thermal conductivity and wide band gap energy of $\mathrm{SiC}$, operation in high temperature is allowed to $\mathrm{SiC}$ devices which make them more preferred for harsh environment applications.

Recently, two classes of $\mathrm{SiC}$ power electronic devices are commercially available, namely Schottky diodes and transistors. SiC Schottky diodes are available from several manufacturers, including Infineon, Cree, IXYS, Microsemi, and STMicroelectronics, etc. The high voltage ratings to $1200 \mathrm{~V}$ and the near zero reverse recovery time of these devices, make them excellent choices for many other hard switching applications. Also SiC controllable switching devices in a variety of voltage and current levels are available as engineering samples such as JFETs from SemiSouth, MOSFETs from Cree, and BJTs from TranSiC.

\section{A. Normally-off SiC JFET}

One of the most successful and promising device to replace Si-MOSFET and IGBT is the normally-off SiC JFET. The SiC JFET is the controlled turn on-off $\mathrm{SiC}$ device which is close to commercialization and is available as restricted samples. The SiC JFET is a majority carrier device and its active device structure presents only with P-N junctions. It has been stated that its surge current capability is better than Si power MOSFET, also its on resistance is lower than $10 \mathrm{~m} \Omega \mathrm{cm}^{2}$ and it has very high switching speed due to small intrinsic capacitances, thus it is suitable for high switching frequency high power density application [11].

\section{B. SiC MOSFET}

Recently, SiC MOSFETs have become available and some of its advantages have demonstrated. Because the higher doping and current densities of $\mathrm{SiC}$ material, the SiC MOSFETs have smaller area and capacitance, therefore they are more efficient than Si MOSFETs. The fall time of SiC MOSFET current is smaller, hence switching losses and on state resistance of it is lower than Si MOSFET [12].

The Cree has introduced a $1200 \mathrm{~V} \mathrm{SiC} \mathrm{MOSFET} \mathrm{with} \mathrm{low} \mathrm{on-state} \mathrm{resistance} \mathrm{R}_{\mathrm{ds}}(\mathrm{on})$ of $160 \mathrm{~m} \Omega$, thus removing the upper voltage limit of silicon MOSFETs [13]. It should be noted that high voltage (>1000 V) Si MOSFETs can be manufactured, but due to fairly high $\mathrm{R}_{\mathrm{ds}}(\mathrm{on})$ their application is considered unpractical. 


\section{C. $\mathrm{SiC} B J \mathrm{~T}$}

Many years ago, Si BJT was replaced by Si power MOSFETs and IGBTs due to its low current gain and small safe operating area which was caused by the unique second breakdown problem. Indeed, there is almost no significant Si BJT research activity in the past 20 years, but the emergence of $\mathrm{SiC}$ as new material for power semiconductor devices has led to consider power BJTs as a possible candidate for high power and high voltage application. This is due to some advantages of SiC BJTs in compare with other different $\mathrm{SiC}$ power devices which are normally-off device, very low specific on resistance, positive coefficient of the on resistance, fast switching speed, free from any gate oxide [14]. The 1200V SiC BJTs which have been developed by TranSiC have overcome the problem of the second breakdown found in Si BJTs and also have better performance in terms of conduction and switching losses in compare with 1200V Si IGBTs.

Furthermore, one of the vital parameters of the BJT is the common emitter current gain which is defined as the ratio between the base current and the collector current. It has been reported that the recently fabricated SiC BJTs have a high value for the common emitter current gain [14]. This means that to obtain the same collector current, the SiC BJT will require a smaller base current, therefore minimizing base drive loss.

\section{EXPERIMENTAL ARRANGMENT}

To investigate the switching behavior of $\mathrm{SiC}$ devices and measure the power losses of them, three different 2-phase to 1phase matrix converter with same power layout and PCB trace are implemented. A circuit schematic of 2-phase to 1-phase matrix converter is shown in Fig. 2(a). They are populated by four Normally-off SiC JFETs, SiC MOSFETs and SiC BJTs respectively and four SiC Schottky Diodes which are listed in TABLE I. A prototype of experimental rig of 2-phase to 1-phase SiC MOSFET matrix converter is shown in Fig. 2(b).

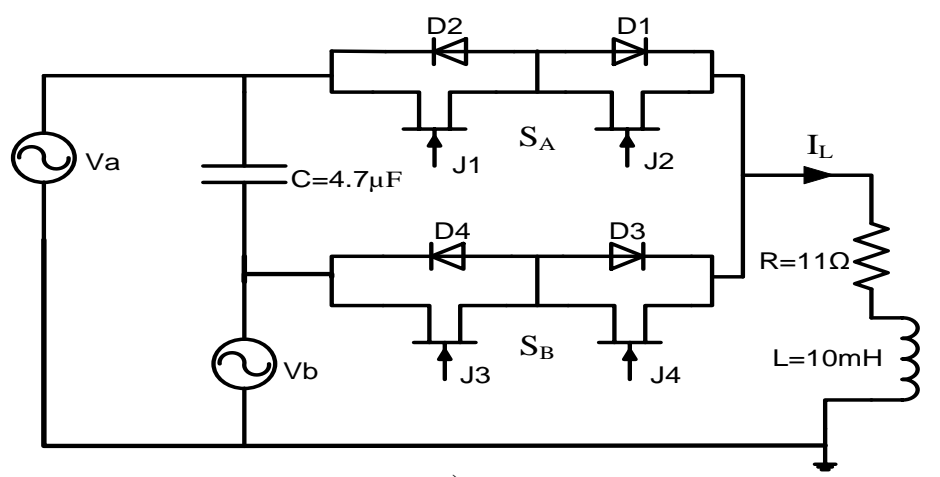

(a)

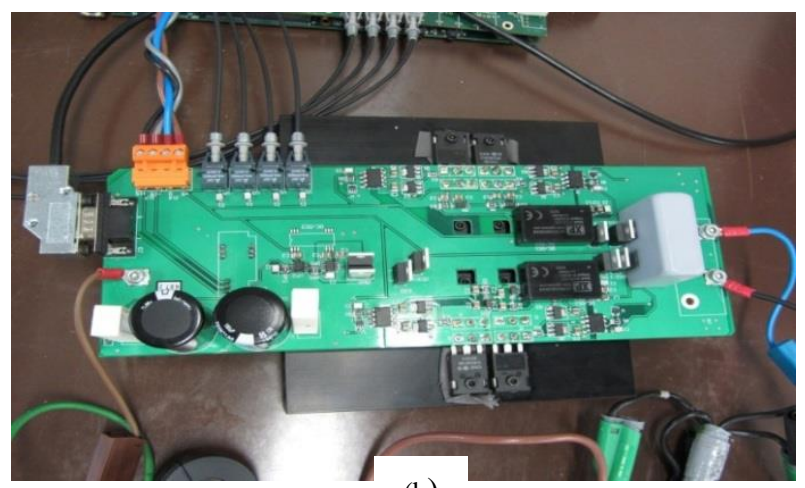

(b)

Fig. 2. 2-phase to 1-phase matrix converter. (a) Schematic of circuit. (b) A prototype of SiC MOSFET matrix converter 
To control the switch sequencing using a four step commutation strategy an FPGA is employed. The switching frequency of converter can be changed and fixed duty cycle switching is used to give equal input and output frequencies. The supply is variable from $0-230 \mathrm{Vrms}, 50 \mathrm{~Hz}$ in each phase and the output current is controlled by adjusting the load resistance. There is a simple capacitive filter which is constructed from ultra-low inductance metalized polypropylene capacitor at the input side which connected directly to the power plants.

TABLE I

DIFFERENT POWER SWITCHING DEVICES WHICH ARE USED IN EVALUATION OF THE MATRIX CONVERTER

\begin{tabular}{|c|c|c|c|c|c|}
\hline Switch & Model & Manufacturer & Voltage $(\mathrm{V})$ & Current (A) & On resistance at $\mathrm{T}_{\mathrm{C}}=25^{\circ} \mathrm{C}(\Omega)$ \\
\hline Si IGBT+ diode & SK20GB123 & Semikron & 1200 & 23 & 0.086 \\
\hline SiC JFET & SJEP120R063 & Semisouth & 1200 & 30 & 0.063 \\
\hline SiC MOSFET & CMF10120D & CREE & 1200 & 24 & 0.160 \\
\hline SiC BJT & BT1215AC & Transic & 1200 & 24 & 0.075 \\
\hline SiC Diode & C4D20120D & CREE & 1200 & 32 & 0.054 \\
\hline
\end{tabular}

The need to develop suitable gate or base drive in pursue of full utilization of the SiC JFET, MOSFET and BJT high speed capabilities has hence become apparent, where the major obstacle faced has been the different requests of SiC components. To solve this problem, several researches have been done to consider special attention which is required [15-19]. In the following section, different requests for driving $\mathrm{SiC}$ power devices and gate or base drives which have been developed and used for implementation of $\mathrm{SiC}$ matrix converter are presented. The gate drive for each device has a similar configuration for the different SiC devices, but the best performance in terms of switching time has been achieved for each SiC switch. The configuration of the drive circuit for $\mathrm{SiC} \mathrm{JFET} \mathrm{and} \mathrm{BJT} \mathrm{is} \mathrm{the} \mathrm{same} \mathrm{but} \mathrm{the} \mathrm{driving} \mathrm{voltage} \mathrm{and} \mathrm{components} \mathrm{are} \mathrm{different} \mathrm{due}$ to the requirements of device. An Ixys IXDN609SI as a high speed gate driver with low voltage rise and fall times has been used in all designed drive circuits to have similar conditions in all tests.

\section{A. Normally-off SiC JFET Gate Drive}

Normally-off SiC JFET makes special demands on the gate driver circuit compared to other unipolar SiC or Si devices. To fully exploit the potential of normally-off SiC JFETs, conventional gate driver circuits for unipolar switches need to be adapted for use with these switches. As it has been stated in [20], during on-state the gate-source voltage must not exceed $3 \mathrm{~V}$, while a current of around $150 \mathrm{~mA}$ (depending on the desired on-resistance) must be fed into the gate, during switching operation the transient gate voltage should be around $\pm 15 \mathrm{~V}$ and the low threshold voltage of less than $0.7 \mathrm{~V}$ requires a high noise immunity which is a severe challenge as the device has a comparably low gate-source but high gate-drain capacitance. 
In the existing two stage gate drive [21], one stage supplies a short pulse with a high voltage for turn-on and a second stage delivers the DC gate current for the on-state. Although the performance of this kind of gate drive is suitable, it still features high circuit complexity, a high part count, and a large printed circuit board footprint.

A gate drive circuit is developed in order to overcome the current limitations while still having a low circuit complexity. In the developed gate drive which is shown in Fig. 3(a) is based on AC coupling circuit. It is consist of a gate resistor and a speed up capacitor. The gate resistor is used to set the DC operating point in the on state by dropping the potential difference between the high level output of the gate drive IC and the required gate source voltage of the SiC JFET at a specified gate current. The speed up capacitor is used to rapidly deliver or remove the dynamic gate charge for a fast turn on and off. When the input capacitance of SiC JFET is fully charged steady state conditions will be regulated by the gate resistor. An additional low resistance is included in series with the speed up capacitor to dampen any observed gate ringing. The proposed gate drive circuit is designed to control a 1.2 kV-30 A normally-off SiC JFET (SJEP120R063) from the Semisouth. The other components of the drive circuit are an Ixys IXDN609SI which provide 18V output swing and up to 9A of current and an opto-isolator, the Avago HCPL-3150 which has high common mode transient immunity $(15 \mathrm{kV} / \mu \mathrm{sec})$ and can operate from 15 to $30 \mathrm{~V}$.

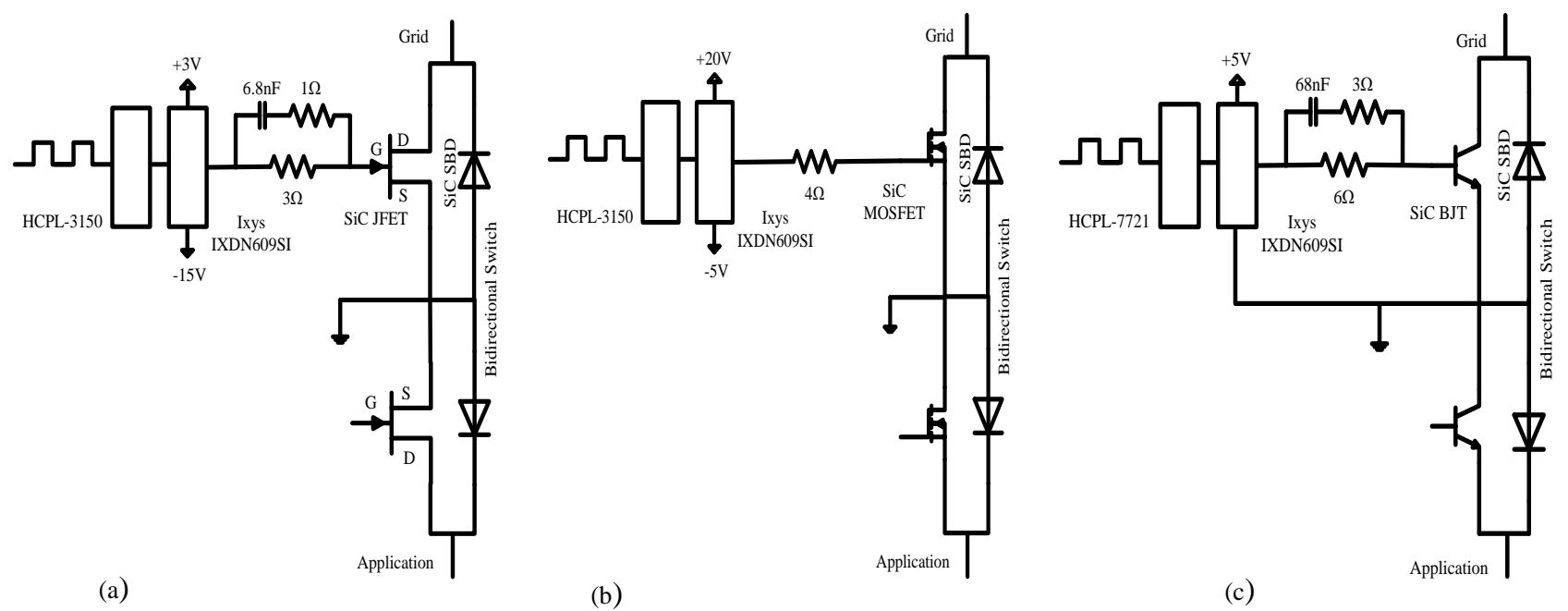

Fig. 3. A schematic diagram of drive circuits for SiC devices. (a) Gate drive of SiC JFET.(b) Gate drive of SiC MOSFET.(c) Base drive of SiC BJT

\section{B. SiC MOSFET Gate Drive}

The proposed gate drive circuit for SiC MOSFET is indicated in Fig. 3(b) and consists of a current limiting resistor. It is designed to control a $1.2 \mathrm{kV}$ - 24 A SiC MOSFET (CMF10120D) from CREE. The other components which are used in drive 
circuit are an Ixys IXDN609SI which provides 25V output swing and up to 9A of current and an optoisolator, the Avago HCPL7721 , which has high common mode transient immunity $(15 \mathrm{kV} / \mu \mathrm{sec})$ and can operate from 15 to $30 \mathrm{~V}$.

\section{SiC BJT Base Drive}

It has been stated that the base drive requirements of $\mathrm{SiC} \mathrm{BJTs}$ are totally different from $\mathrm{Si}$ BJTs [22]. This is due to the $\mathrm{SiC}$ BJT does not rely on high injection and there is no problems with storage times at turn off. Also if the reverse base current during the turn off is too high, the SiC BJT does not have problem with trapped charge [23]. Thus, these features make it clear that the design criteria of SiC BJT are different from Si BJT.

As it is mentioned, the main argument against the $\mathrm{SiC} \mathrm{BJT}$ is the base current when it is in the on state due to it must be produced by the base drive circuit and the amount of required base current is not negligible. Typical values of the common emitter gain are of the order 60, which mean that a $30 \mathrm{~A}$ SiC BJT would need a base current of the order of 0.5A[23].

A well-known base drive circuit that improves the switching transients is an AC coupling circuit which is illustrated in Fig.3(c). It is consists of a base resistor and a speed up capacitor in parallel with resistor. The capacitor is charged up to a voltage level equal to the voltage difference between $V_{C C}$ and $V_{B E(S A T)}$ during the turn on transition of SiC BJT and so creating a low impedance path for the base current. In addition, the capacitor provides a negative voltage which applied across the base emitter terminals during the turn off transition of the SiC BJT. This causes improvement in the turn off transient.

The proposed base drive circuit is designed to control a $1.2 \mathrm{kV}-24$ A SiC BJT (BT1215AC) from TranSiC. The main component of the circuit is an Ixys IXDN609SI which can provide 5Voutput swing and up to 9A of current. The optoisolator, the Avago HCPL-7721, has high common mode transient immunity $(10 \mathrm{kV} / \mu \mathrm{sec})$ and can operate from 4.5 to $5.5 \mathrm{~V}$.

\section{SWItChing PERFormance EVAluation}

To investigate experimentally performance of different $\mathrm{SiC}$ power devices in matrix converter, the current and voltage switching waveforms for all $\mathrm{SiC}$ power devices in each of the three $\mathrm{SiC}$ matrix converters were measured under identical operating conditions. Then, the input and output power of three matrix converters in different temperatures and switching frequencies are measured in order to extract the power loss from them.

\section{A. Turn on waveform}

With implemented $\mathrm{SiC}$ matrix converters, turn on switching performance of $\mathrm{SiC}$ power devices has been tested in various temperatures and load currents. The waveforms of drain-source voltage and drain current for turning on the normally-off SiC 
JFET in matrix converter when the case temperature of device is $25^{\circ} \mathrm{C}$ is shown in Fig.4(a). It is obvious that the switching turn on time is slightly less than $50 \mathrm{~ns}$.

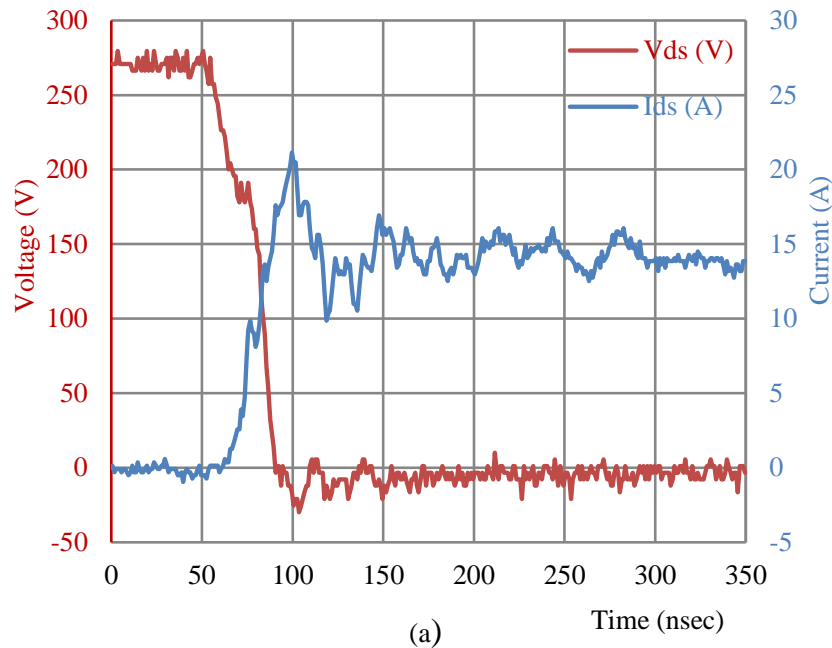

(a)

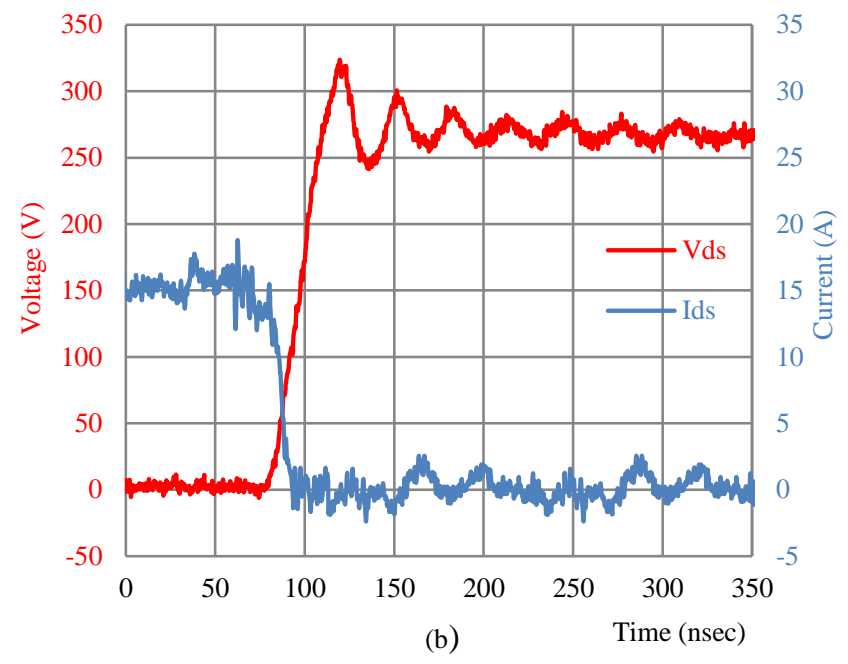

(b)

Fig. 4. Switching waveforms of the normally-off $\mathrm{SiC} J F E T$ at $\mathrm{V}_{\mathrm{Sw}}=270 \mathrm{~V}$ and $\mathrm{I}_{\mathrm{Sw}}=15 \mathrm{~A}$ when $\mathrm{T}_{\mathrm{C}}=25^{\circ} \mathrm{C}$. (a) Turn on switching waveform. (b) Turn off switching waveform
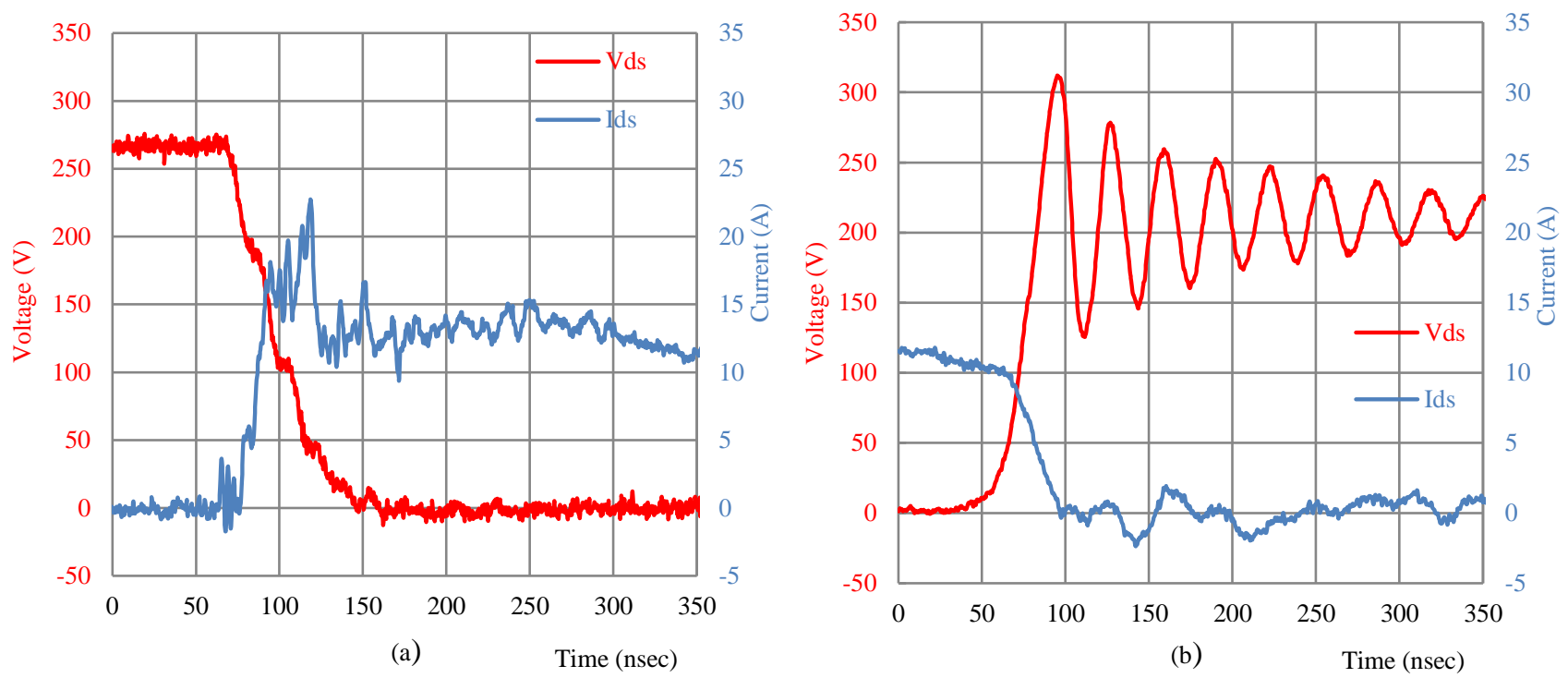

Fig. 5. Switching waveforms of the $\mathrm{SiC}$ MOSFET at $\mathrm{V}_{\mathrm{SW}}=270 \mathrm{~V}$ and $\mathrm{I}_{\mathrm{SW}}=13 \mathrm{~A}$ when $\mathrm{T}_{\mathrm{C}}=25^{\circ} \mathrm{C}$. (a) Turn on switching waveform. (b) Turn off switching waveform 

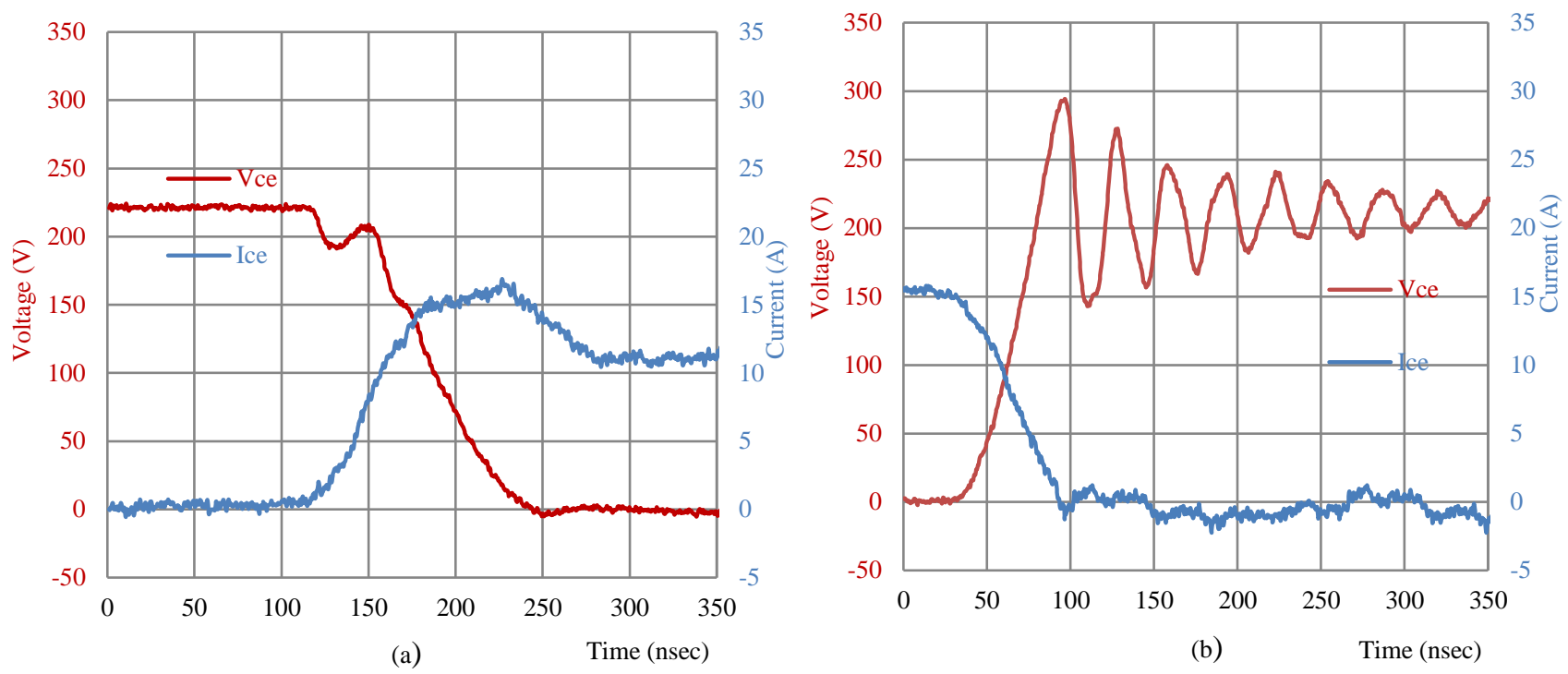

Fig. 6. Switching waveforms of the SiC BJT at $\mathrm{V}_{\mathrm{SW}}=230 \mathrm{~V}$ and $\mathrm{I}_{\mathrm{SW}}=15 \mathrm{~A}$ when $\mathrm{T}_{\mathrm{C}}=25^{\circ} \mathrm{C}$. (a) Turn on switching waveform. (b) Turn off switching waveform

In addition, Fig.5(a) shows the waveforms of drain-source voltage and drain current for turning on the SiC MOSFET in matrix converter when the case temperature of device is $25^{\circ} \mathrm{C}$. It is clear that the switching turn on time is slightly more than $80 \mathrm{~ns}$. Moreover, the waveforms of collector-emitter voltage and collector current for turning on the SiC BJT in matrix converter when case temperature of devices is $25^{\circ} \mathrm{C}$ is illustrated in Fig.6(a). Based on the illustrated waveform for SiC BJT, it can be stated that turning on time of $\mathrm{SiC} \mathrm{BJT}$ is about $140 \mathrm{~ns}$ which is more than two other SiC switches.

\section{B. Turn off waveform}

The waveforms of drain to source voltage and drain current during turning off process of the normally-off SiC JFET in matrix converter when case temperature of devices is about $25^{\circ} \mathrm{C}$ is indicated in Fig.4(b). It is clear that the switching turn off time when the voltage across the switch and load current are $260 \mathrm{~V}$ and $15 \mathrm{~A}$ respectively is slightly more than $65 \mathrm{~ns}$. Furthermore, the waveforms in Fig.5(b) shows drain to source voltage and drain current during turning off process of the SiC MOSFET in matrix converter. It is obvious that the turning off time of it when the voltage across the device and load current are $220 \mathrm{~V}$ and $13 \mathrm{~A}$ respectively is slightly more than $85 \mathrm{~ns}$. Moreover, the turning off time of SiC BJT in matrix converter when the temperature of devices case, voltage across collector-emitter of device and load current are $25^{\circ} \mathrm{C}, 210 \mathrm{~V}$ and $15 \mathrm{~A}$ respectively is about $55 \mathrm{~ns}$, based on presented waveform in Fig.6(b). There is overshoot and distinct oscillation in waveform of turning off voltage of $\mathrm{SiC}$ devices which is due to parasitic inductance of PCB circuit. 


\section{Switching Energy Losses}

In order to estimate the switching loss of a three phase matrix converter in future section, it is needed to know the value of the energy loss during turning on and off process of each $\mathrm{SiC}$ devices. Therefore, the switching energy losses of SiC power devices were calculated in different temperatures and currents. Indeed, the switching characterization has been done for current up to $20 \mathrm{~A}$ when the input voltage is $250 \mathrm{~V}$ and the case temperature is 25 and $125^{\circ} \mathrm{C}$. The switching energy loss was calculated by the integration of the instantaneous power waveform (drain-source (collector-emitter) voltage waveform multiplied by drain (collector) current waveform). In addition, Fig. 7 shows the switching energy losses of Normally-off SiC JFET, SiC MOSFET and $\mathrm{SiC} \mathrm{BJT}$ in different temperatures and currents when they are employed in matrix converter. It is seen that the SiC MOSFET has a larger total switching energy loss than Normally-off SiC JFET and SiC BJT. Also by increasing the temperature, the switching energy loss of SiC MOSFET has been increased significantly in compare with Normally-off SiC JFET and SiC BJT.
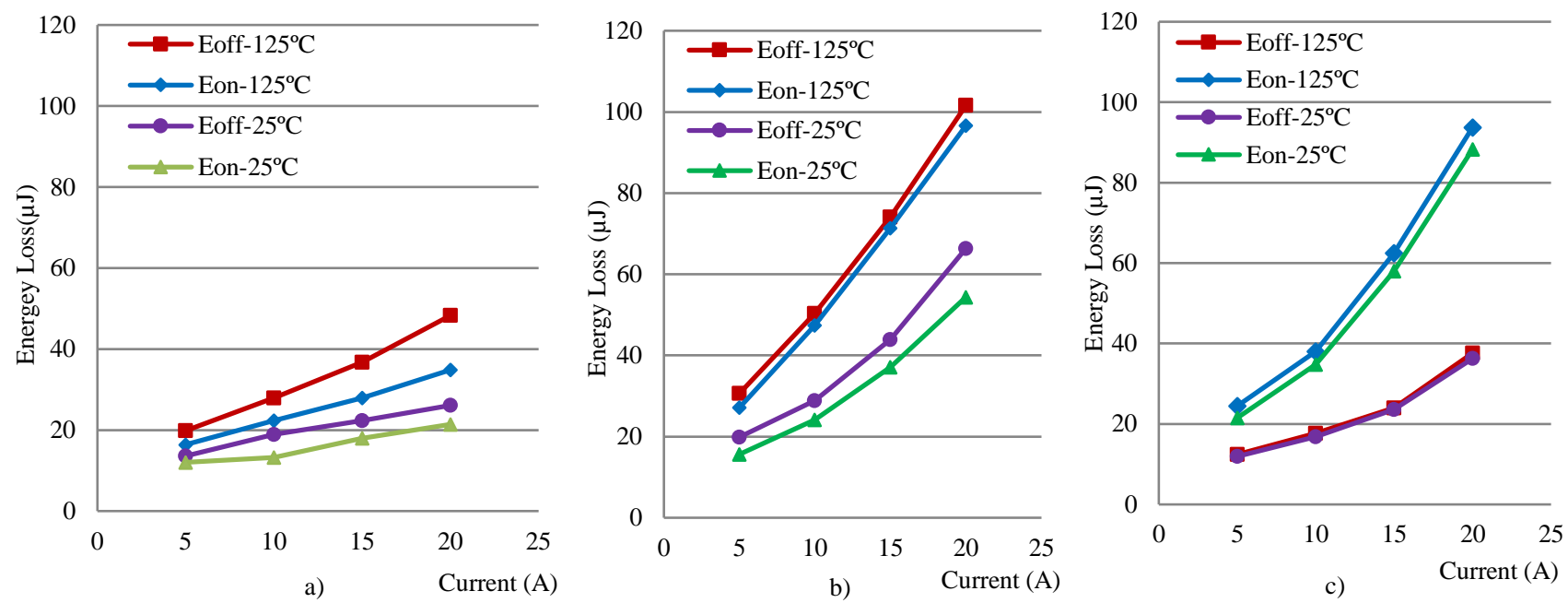

Fig. 7. Switching energy losses of $\mathrm{SiC}$ power devices in different load currents and temperatures at $\mathrm{V}_{\mathrm{Sw}}=250 \mathrm{~V}$. (a) Normally-off $\mathrm{SiC}$ JFET.(b) SiC MOSFET.(c) SiC BJT

\section{Performance Evaluation of SiC Matrix Converter}

The switching waveforms which indicted in Fig. 4, 5 and 6 are suitable for comparing switching phenomena in terms of voltage overshoot; turn on and off times of switching and switching energy losses. The power loss can be determined by measuring the input and output power of matrix converter. The instantaneous input and output powers can be determined by measuring input and output currents and voltages. This was done using differential voltage probe and Hall Effect current probe. Then the input and output powers of matrix converter were determined by multiplying the current and voltage of them. The instantaneous powers were integrated over several cycles of the input and output waveforms at the sampling frequency of 
$500 \mathrm{MHz}$ to ensure good accuracy in calculating. The advantage of using this method is that any random errors for instance due to noise, will tend to cancel.

In order to compare the performance of the three $\mathrm{SiC}$ power devices in terms of the overall efficiency and the power loss, the input and output powers are measured over a wide range of switching frequency and different operating temperatures. Different heatsinks have been employed to change the case temperature of switches.

Figure 8 shows the measured power losses of matrix converter when different $\mathrm{SiC}$ devices have been employed in it based on the switching frequency in different operating temperatures for $2.5 \mathrm{~kW}$ converter. It is obvious that the power loss of $\mathrm{SiC}$ BJT matrix converter is less than the SiC JFET and MOSFET matrix converters. It is clear that by increasing the switching frequency, there is no significant increasing in the power losses of $\mathrm{SiC}$ matrix converters.
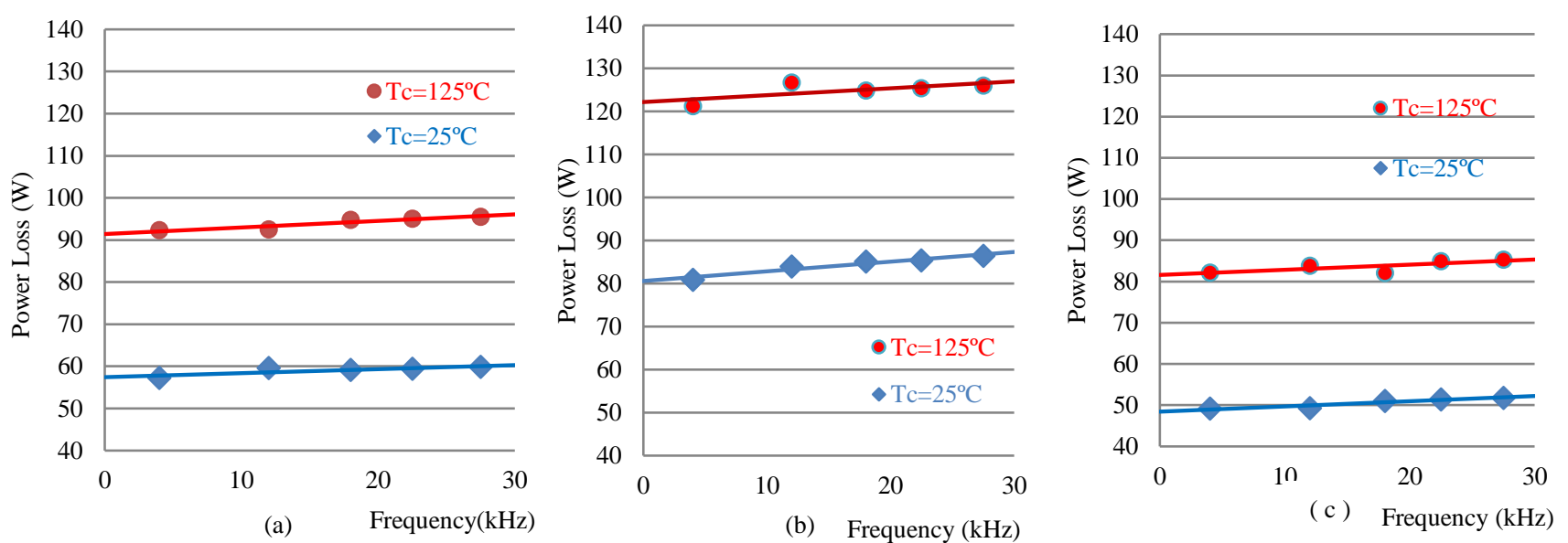

Fig. 8. Measured power losses of $2.5 \mathrm{~kW} \mathrm{SiC}$ matrix converter in different switching frequencies and temperatures. (a) SiC JFET.(b) SiC MOSFET.(c) SiC BJT

Furthermore, the switching loss per unit switching frequency $\left(P_{s w}\right)$ can be calculated from the gradient of power loss curve in Fig. 8. Also the conduction loss $\left(P_{c o n}\right)$ of matrix converter can be determined from the intersection of power loss curve with zero switching frequency in Fig. 8. The values listed in TABLE II are taken from results presented in Fig.8.

Due to same $\mathrm{SiC}$ diode has been used with three different $\mathrm{SiC}$ devices in matrix converter, so the difference in the conduction losses of $\mathrm{SiC}$ matrix converters is because of different kind of $\mathrm{SiC}$ power devices. In the other hand, due to conduction loss of SiC JFET, MOSFET and BJT only depends to the on resistance of devices and load current, thus, it can be stated that the on resistance of SiC MOSFET is more than SiC JEFT and BJT. It is interesting to note that the conduction loss of SiC MOSFET matrix converter has been increased more than conduction loss of two other $\mathrm{SiC}$ matrix converters by increasing temperature, so it can be concluded that the on resistance of SiC MOSFET is increased more by increasing temperature 
TABLE II

MEASURED POWER LOSSES FOR THE SIC MATRIX CONVERTER IN VARIOUS TEMPERATURES

\begin{tabular}{|c|c|c|c|c|c|c|}
\hline & \multicolumn{2}{|c|}{ SiC JFET Matrix Converter } & \multicolumn{2}{c|}{ SiC MOSFET Matrix Converter } & \multicolumn{2}{c|}{ SiC BJT Matrix Converter } \\
\hline Temperature $\left({ }^{\circ} \mathrm{C}\right)$ & $\mathrm{P}_{\text {con }}(\mathrm{W})$ & $\mathrm{P}_{\mathrm{sw}}(\mathrm{W} / \mathrm{kHz})$ & $\mathrm{P}_{\text {con }}(\mathrm{W})$ & $\mathrm{P}_{\mathrm{sw}}(\mathrm{W} / \mathrm{kHz})$ & $\mathrm{P}_{\text {con }}(\mathrm{W})$ & $\mathrm{P}_{\mathrm{sw}}(\mathrm{W} / \mathrm{kHz})$ \\
\hline 25 & 57.43 & 0.095 & 80.58 & 0.224 & 48.44 & 0.126 \\
\hline 125 & 91.40 & 0.155 & 122.18 & 0.159 & 84.60 & 0.124 \\
\hline
\end{tabular}

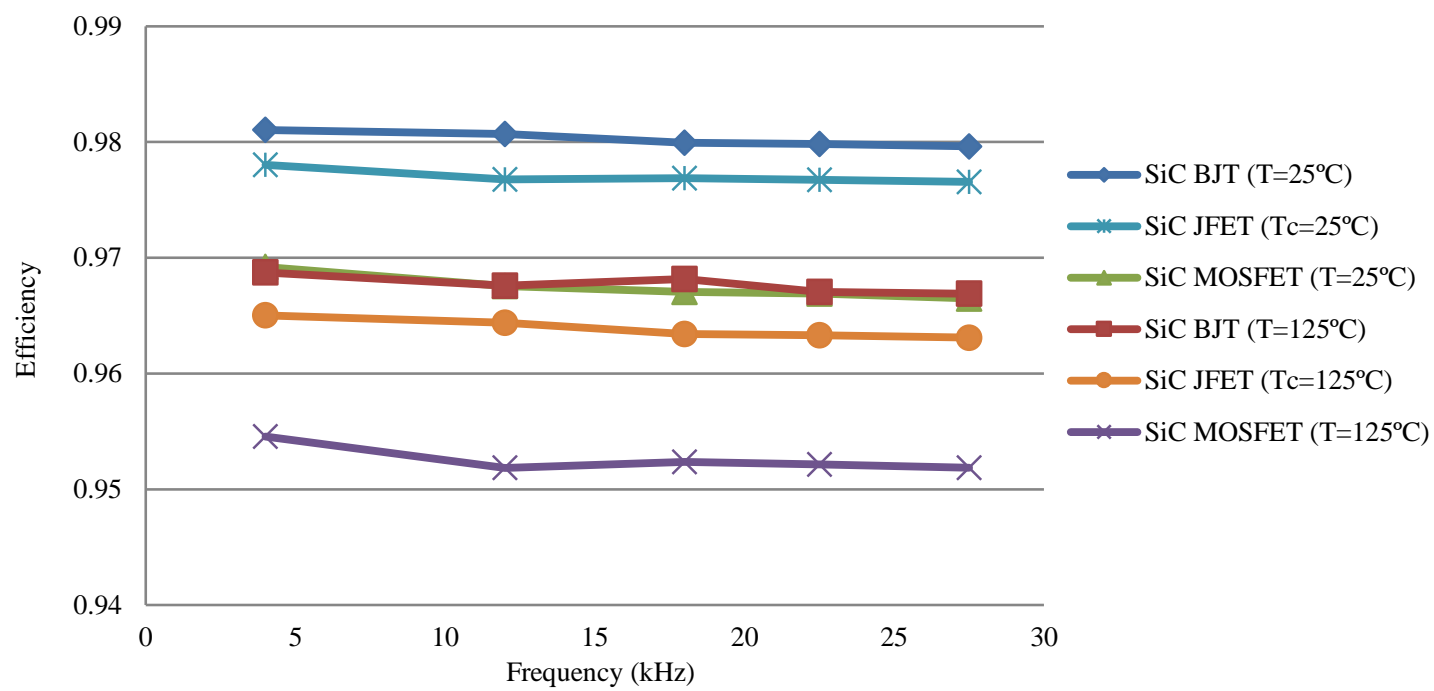

Fig. 9.: Efficiency of 2-phase to 1-phase of 2.5kW SiC matrix converter based on switching frequency in different temperatures

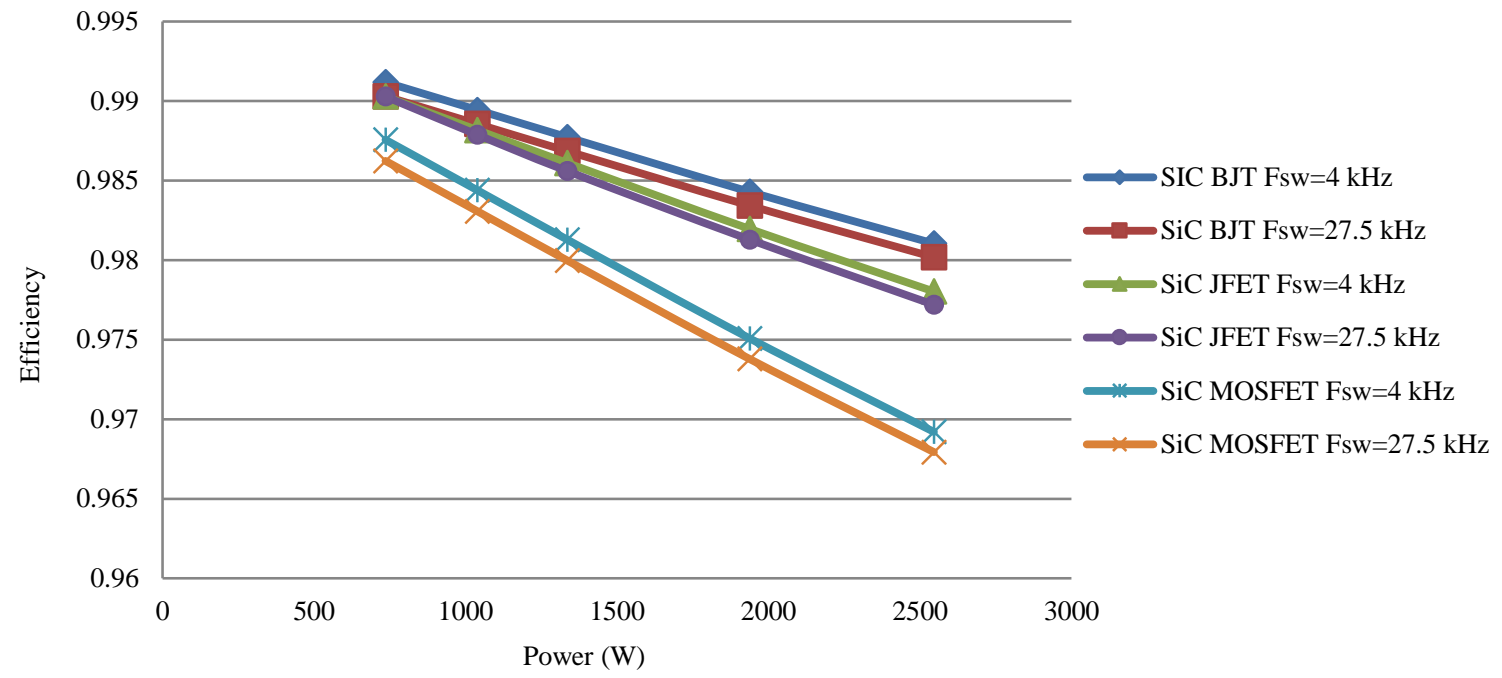

Fig. 10.: Efficiency of 2-phase to 1-phase $\mathrm{SiC}$ matrix converter based on output power in different switching frequencies at $\mathrm{T}_{\mathrm{C}}=25^{\circ} \mathrm{C}$

In addition based on the measured input and output power of matrix converter for various switching frequencies and temperatures, the efficiency has been determined which has been illustrated in Fig.9. It is clear that the efficiency of SiC matrix converters are slightly varied by changing switching frequency and temperature. Also, the efficiency of three SiC matrix converters is more than $95 \%$ in high frequency and high temperature. Furthermore, Fig.10 illustrates the efficiency of the three 
$\mathrm{SiC}$ matrix converters based on the output power in different switching frequencies. It is obvious that the efficiency variation of SiC JFET and BJT matrix converters is less than SiC MOSFET matrix converter.

\section{POWER Loss Evaluation In Three Phase Matrix CONVERTER}

One of the basic steps for evaluation of the reliability of matrix converter is power loss analysis. Due to converting AC utility voltages into variable voltage outputs in matrix converter by nine bidirectional switches, the drain-source or collector-emitter voltage of JFET and MOSFET or BJT and IGBT switches are not constant at each switching instant. Also due to rotation of voltage angle of utility grid, the current distributions in each switch changes. For these reasons, evaluation of switching losses in matrix converter requires conceptual understanding of switching rules and physical characteristics of switches and diodes.

Calculation of conduction loss and switching loss for matrix converter has been conducted in [24-26].

This part of paper presents an analytical method for evaluating power losses of three phase matrix converter with $\mathrm{Si}$ and $\mathrm{SiC}$ power devices and then comparison of them. Power device losses of matrix converter consist of drive, conduction and switching losses of diodes and switch devices such as Si IGBT and SiC JFET, MOSFET or BJT. In the calculation of conduction loss in next section, the on resistance and on state voltage of devices have been extracted from the device datasheet, while in calculation of matrix converter switching losses, the measured switching energies from 2-phase matrix converters in previous section have been used.

\section{A. Drive Losses}

Power consumption in the drive circuit is required to consider in determining the efficiency of whole converter. The drive losses in various power switching devices is different and it depends on the characteristics of switch and drive circuit.

For the normally-off SiC JFET, three contributions of the power consumption must be considered in calculation the drive losses based on the used gate drive circuit in previous section. The first one is associated with charging of the gate capacitance during each turn on transient. The second one is due to on state resistance of the gate drive and the last one is associated with charging of speed up capacitor in the gate drive. Therefore the total drive loss for the normally-off SiC JFET can be presented as:

$$
P_{\text {drive-JFET }}=V_{g s} Q_{g} f_{s}+I_{g r m s}^{2} R_{g}+C_{s} f_{s}\left(V_{c c}-V_{g s}\right)^{2}
$$

In the above equation, $V_{g s}$ is the forward voltage bias, $Q_{g}$ is the gate charge of JFET, $f_{s}$ is the switching frequency, $I_{g r m s}$ is the rms value of the gate current, $R_{g}$ is the gate resistor, $C_{s}$ is the speed up capacitor and $V_{c c}$ is the supply voltage in turn on time. 
In addition, the drive loss of SiC MOSFET and Si IGBT only consists of the charging of the gate capacitance during each turn on transient. Therefore it can be stated as:

$$
P_{\text {drive-MOSFET or IGBT }}=V_{g s} Q_{g} f_{S}
$$

In the above equation, $V_{g s}$ is the forward voltage bias, $Q_{g}$ is the gate charge of MOSFET or IGBT and $f_{s}$ is the switching frequency.

Furthermore, for determining the base drive losses of $\mathrm{SiC} \mathrm{BJT}$, it is needed to consider one more contribution of power consumption in compare with normally-off SiC JFET which is due to voltage drop across the base emitter of BJT in on state duration. Therefore, the total base drive losses for the SiC BJT based on the used base drive circuit in this work can be expressed as:

$$
P_{\text {drive-BJT }}=I_{b a v} V_{b e(s a t)}+V_{b e(s a t)} Q_{b} f_{s}+I_{b r m s}^{2} R_{b}+C_{s} f_{s}\left(V_{c c}-V_{b e(s a t)}\right)^{2}
$$

In the above equation, $I_{b a v}$ is the average base current, $V_{b e(s a t)}$ is the voltage drop across based emitter of BJT, $Q_{b}$ is the base charge of BJT, $f_{s}$ is the switching frequency, $I_{b r m s}$ is the rms value of the base current, $R_{b}$ is the base resistor, $C_{s}$ is the speed up capacitor and $V_{c c}$ is the supply voltage in turn on time.

Therefore, by considering a typical double sided space vector modulation for matrix converter, the total driving loss of the three phase matrix converter can be calculated by:

$$
P_{\text {drive }}=12 P_{\text {drive-JFET or MOSFET or BJT or IGBT }}
$$

\section{B. Conduction Losses}

Conduction losses of switching devices in matrix converter have been covered in [25, 27]. In fact, the output current flow through one switching devices such as JFET or IGBT and one diode at any instant, thus based on the balanced three phase output currents some equations have been derived to determine conduction losses with depend on the model of switch [27]. By assuming a sinusoidal output current of rms magnitude $I_{0}$, the average conduction losses for three phase matrix converter for different switch devices is given by:

$$
\begin{aligned}
& P_{c o n}=\frac{6 \sqrt{2}}{\pi} V_{c e} I_{o}+3 r_{c e} I_{o}^{2} \quad \text { (5) (for Si IGBT) } \\
& P_{\text {con }}=3 r_{d s} I_{o}{ }^{2} \quad \text { (6) (for SiC JFET, MOSFET and BJT) } \\
& \left.P_{\text {con }}=3 r_{c e} I_{o}{ }^{2} \quad \text { (7) (for } \mathrm{SiC} \mathrm{BJT}\right) \\
& P_{c o n}=\frac{6 \sqrt{2}}{\pi} V_{f} I_{o}+3 r_{d} I_{o}^{2} \quad \text { (8) (for Si or SiC Diode) }
\end{aligned}
$$


In the above equation, $V_{c e}$ is the on-state collector-emitter voltage of IGBT switch and $r_{c e}$ is on state resistance of IGBT or BJT switch. Also $r_{d s}$ is on state resistance of JFET or MOSFET and $V_{f}$ and $r_{d}$ are the diode forward voltage drop at zero current and the on state resistance of diode respectively.

It is obvious that the conduction loss is only calculated by the rms value of the output current and the operation conditions such as modulation index or switching frequency do not have any effect.

\section{Switching Losses}

The turn on and turn off energy losses for a power electronic switch can be assumed to vary linearly with the change in voltage across the power electronic switch during the switching transient [25]. Also, it is reasonable to assume that the turn on and turn off energy losses varies linearly with the blocking voltage and the conducting current of power electronic switch at the instant of switching event [25]. Hence, the rate of turn on and off of switching energy losses at the reference voltage and current are computed using the following equations:

$$
\begin{gathered}
E_{o n}=\frac{e_{o n}}{V_{R} I_{R}} \\
E_{o f f}=\frac{e_{o f f}}{V_{R} I_{R}}
\end{gathered}
$$

In the above equations, $e_{o n}$ and $e_{o f f}$ are the turn on and turn off energy losses of switching device respectively. $V_{R}$ is the reference voltage in the drain-source or collector-emitter of JFET and MOSFET or BJT and IGBT respectively. $I_{R}$ is the reference current in the drain or collector of JFET and MOSFET or BJT and IGBT respectively.

Similarly the rate of diode reverse recovery or turn off switching energy loss is determined using:

$$
E_{r e c}=\frac{e_{r e c}}{V_{R} I_{R}}
$$

In the above equation, $e_{r e c}$ is the diode recovery or turn off energy loss. $V_{R}$ is the reference voltage across the diode and $I_{R}$ is the reference current of the diode.

In the other hand, for calculating switching losses, it is important to know the mechanisms of commutation due to its effect on switching. Commutation in matrix converter is not as straightforward as in conventional inverters since there are no natural free-wheeling paths. In a matrix converter, the commutation between two bidirectional switches is dependent on both the direction of the output current and the input voltage across the switches undergoing commutation [10]. 


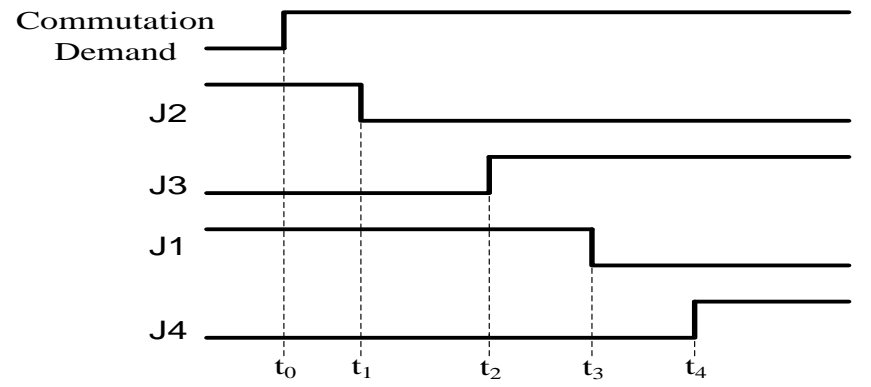

Fig. 11. Timing diagram indicting typical device sequencing when using a four step commutation strategy

Different commutation schemes are possible depending on the direction of the load current, and the relative potentials of input voltage. The device gate timings for a four step commutation strategy when commutating from $S_{A}$ to $S_{B}$ with the load current, $\mathrm{I}_{\mathrm{L}}$ in the direction indicated in Fig.2 (a) is shown in Fig. 11. If input voltage is positive, commutation will occur at $t_{3}$ resulting in a hard turn-off in $\mathrm{S}_{\mathrm{A}}(\mathrm{J} 1)$ and a soft turn-on in $\mathrm{S}_{\mathrm{B}}(\mathrm{J} 3)$. Conversely, if input voltage is negative, commutation takes place at $t_{2}$ resulting in a hard turn-on in $S_{B}(J 3)$ and a soft turn-off in $S_{A}(J 1)$. It is worth to note that, there is no switching loss at all in $\mathrm{J} 2$ and $\mathrm{J} 4$ for either situation, since neither conduct current when $\mathrm{I}_{\mathrm{L}}$ is positive. A similar, but different sequence of events to that above occurs for negative $\mathrm{I}_{\mathrm{L}}$. The soft commutations are not completely lossless, but the energy involved is at least an order of magnitude less than for the hard commutations.

As it has been stated in [24], the observation from the four step commutation scheme can be generalized that there are one turn on loss transient, and one turn off loss transient for the switches and also one reverse recovery energy loss for diode in each commutation event. So by considering symmetry of the balance three phase systems at the input and output terminals of three phase matrix converter, the total switching energy loss of one phase in one switching cycle can be determined by:

$$
E_{s w}=\left(E_{o n}+E_{o f f}+E_{r e c}\right)\left(\left|V_{12}\right|+\left|V_{23}\right|\right)\left|i_{o 1}\right|
$$

In the above equation, $V_{12}$ and $V_{23}$ are phase to phase voltage and $i_{o l}$ is the output current of matrix converter.

By considering that the switching frequency is much higher than the fundamental frequency of input voltage and output current and also a typical double sided space vector modulation, the total switching loss of the three phase matrix converter can be calculated by:

$$
P_{s w}=\frac{24 \sqrt{3}}{\pi^{2}} f_{s}\left(E_{\text {on }}+E_{\text {off }}+E_{r e c}\right) V_{i} I_{o}
$$

In the above equation, $f_{s}$ is the switching frequency of matrix converter and also $V_{i}$ and $i_{o}$ are peak value of input voltage and output current of matrix converter respectively.

D. Comparison of Power Losses in Matrix Converter with various power electronic switches 
To determine and evaluate power losses in matrix converter with various power switching devices three phase matrix converter is considered and four-step commutation strategy is applied. Also, it is considered four kind of matrix converter with four different switching devices for calculating and comparing the power losses of matrix converter. Four different switch devices which are used in evaluation of matrix converter are listed in TABLE I. Input rms voltage and frequency of matrix converter are $230 \mathrm{~V}$ and $50 \mathrm{~Hz}$ respectively and output rms voltage and frequency of matrix converter are set $150 \mathrm{~V}$ and 400 $\mathrm{Hz}$ respectively. The value of the resistance and inductance of the load which are supplied by matrix converter are $10 \Omega$ and $1.3 \mathrm{mH}$ respectively.

Based on the mentioned equations for calculating drive, conduction and switching losses, determined conduction losses and switching energies in previous section and some parameters from the gate or base drive circuit and datasheet of power switching devices, the drive, conduction and switching losses of matrix converter for various switching devices are determined. Figure 12 shows the comparison of the drive loss, conduction loss and switching loss between Si IGBTs, SiC MOSFETs, SiC JFETs and $\mathrm{SiC} \mathrm{BJTs} \mathrm{in} \mathrm{three} \mathrm{phase} \mathrm{matrix} \mathrm{converter} \mathrm{when} \mathrm{switching} \mathrm{frequency} \mathrm{and} \mathrm{output} \mathrm{power} \mathrm{of} \mathrm{converter} \mathrm{are} 80 \mathrm{KHz}$ and $7 \mathrm{KW}$ respectively. It can be stated that there is a significant decreasing in switching losses of SiC matrix converter due low switching energy losses of SiC BJT, JFET and MOSFET in compare with Si IGBT. Also there is no on state voltage across drain-source of $\mathrm{SiC}$ JFET or collector-emitter of $\mathrm{SiC}$ BJT, so conduction loss in SiC JFET and SiC BJT is lower than Si IGBT. It is worth to mention that due to high on resistance of SiC MOSFET in compare by other devices, the total conduction loss of SiC MOSFETs are more than Si IGBTs and other SiC devices in matrix converter, although there is no on state voltage across drain-source of SiC MOSFET. It is worth to mention that the amount of drive loss of SiC BJT is not significant in compare by other kind of losses so the total power losses of a SiC BJT matrix converter has not been affected dramatically due to drive loss of SiC BJTs. 


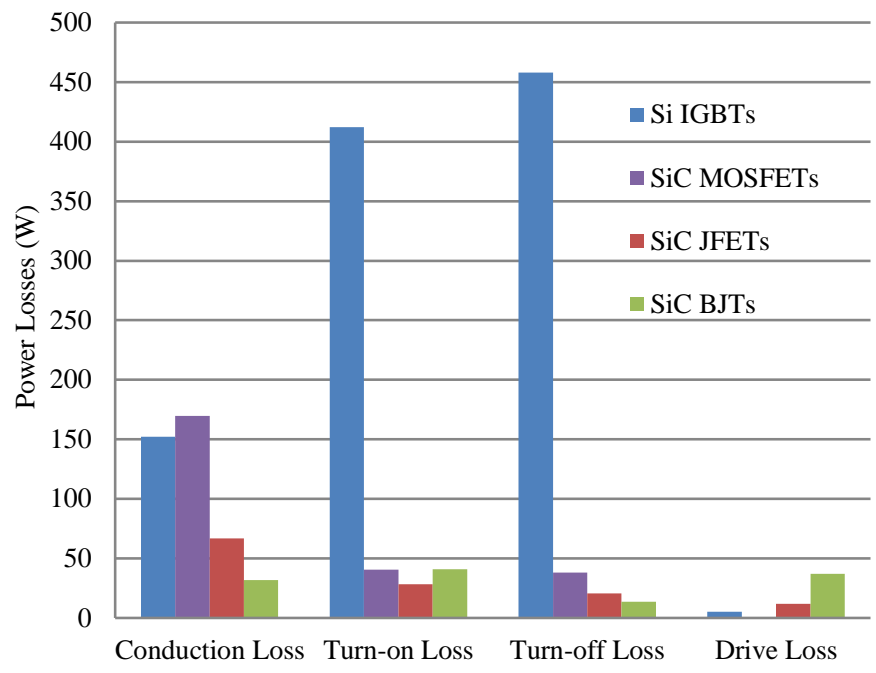

Fig. 12. Drive, conduction and switching losses of $\mathrm{Si}$ and $\mathrm{SiC}$ power devices in a $7 \mathrm{KW}$ three phase matrix converter when switching frequency is $80 \mathrm{kHz}$ at $\mathrm{T}_{\mathrm{C}}=25^{\circ} \mathrm{C}$.

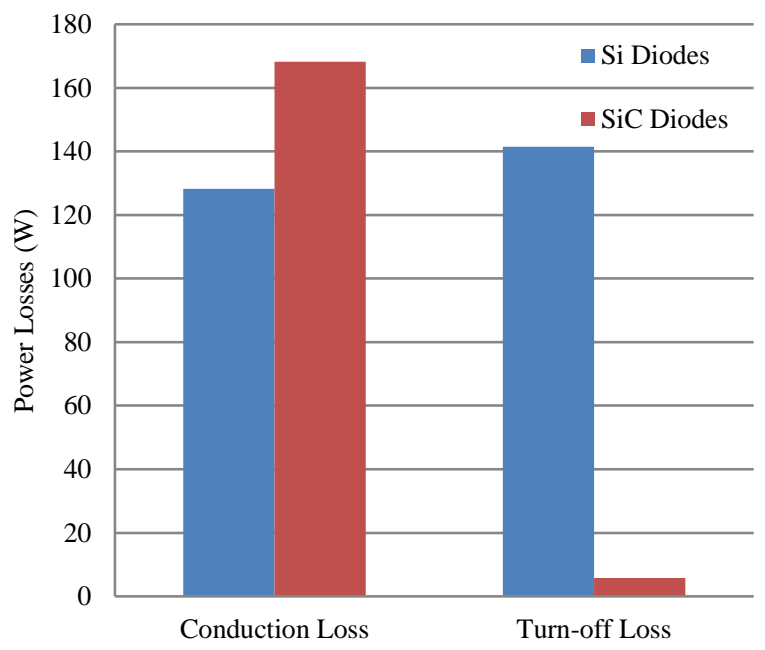

Fig. 13. Conduction and switching losses of $\mathrm{Si}$ diode and $\mathrm{SiC}$ schottky diode in a $7 \mathrm{KW}$ three phase Matrix converter when switching frequency is $80 \mathrm{kHz}$ at $\mathrm{T}_{\mathrm{C}}=25^{\circ} \mathrm{C}$.

In addition, Fig. 13 shows the comparison of the conduction and turn-off losses between Si diodes and SiC Schottky diodes which are used in three phase matrix converter. The most significant difference between Si diode and SiC Schottky diode is in turn off loss due to there is no reverse recovery current in SiC schottky diode in compare with Si diode. 


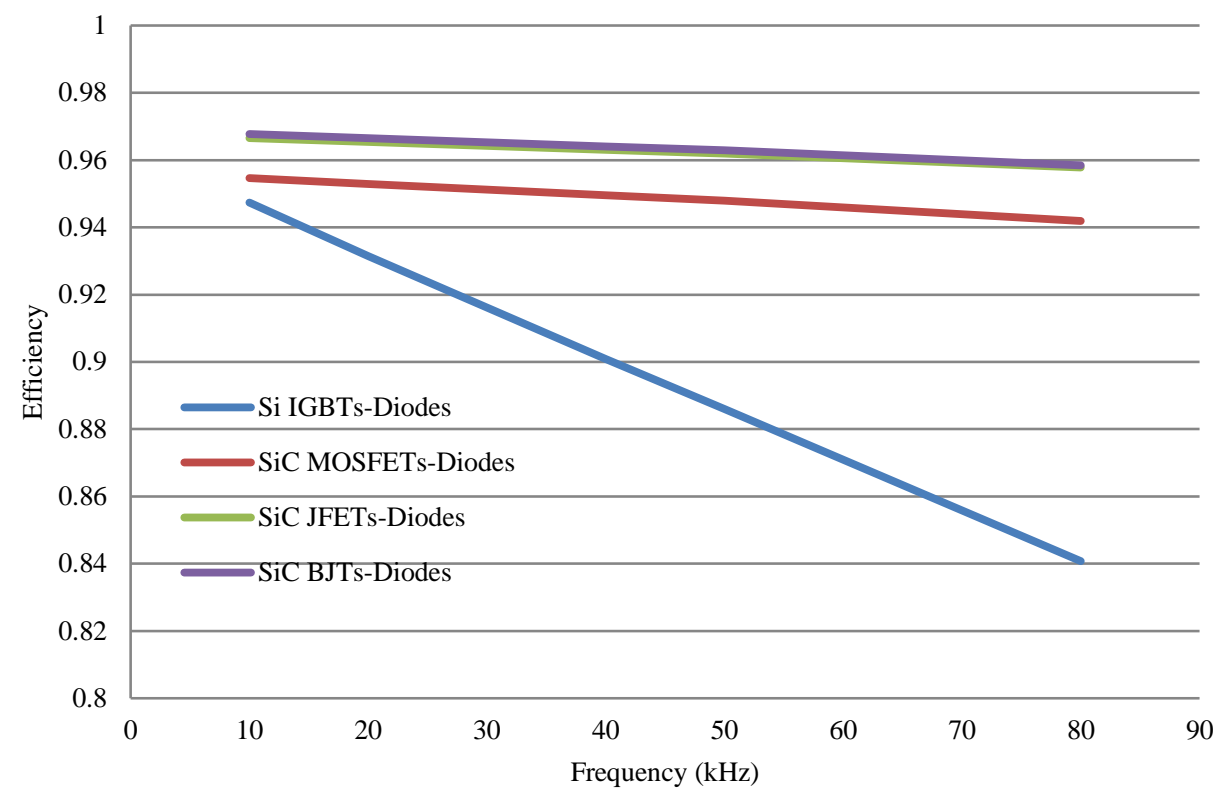

Fig. 14. Calculated efficiency of $7 \mathrm{KW}$ matrix converter for various devices in different switching frequencies at $\mathrm{T}_{\mathrm{C}}=25^{\circ} \mathrm{C}$

The efficiency of the Si and $\mathrm{SiC}$ matrix converters for different switching frequencies when the load that supplied by matrix converter is $7 \mathrm{KW}$ is also studied. The calculation result is shown in Fig. 14. It is obvious that efficiency of a three phase matrix converter which is built by $\mathrm{SiC}$ power devices is not reduced rapidly by increasing the switching frequency in compare with a Si matrix converter. This calculation also shows that high power SiC matrix converter would approximately have an efficiency that exceeds $94 \%$ in high switching frequency when is built by SiC MOSFET or even it can have $96 \%$ when is implemented by normally-off SiC JFET or SiC BJT.

\section{CONCLUSION}

This paper has focused on performance comparison of different $\mathrm{Si}$ and $\mathrm{SiC}$ devices in the matrix converter topology. The study was supported by the measurement of the switching characteristics of normally-off SiC JFET, SiC MOSFET and SiC BJT in bidirectional switch arrangement of 2-phase to 1-phase matrix converter. It has been shown that base on the developed gate or base drives; it is possible to achieve turn on time less than 55, 80 and $140 \mathrm{~ns}$ for SiC JFET, MOSFET and BJT respectively. Also the measured turn off time was less than 65, 85 and $55 \mathrm{~ns}$ for SiC JFET, MOSFET and BJT respectively. Based on the measured input and output power of $\mathrm{SiC}$ matrix converters the performance of them in terms of power loss and efficiency has been investigated in various switching frequencies, load currents and case temperatures. It has been shown that the performance of 2-phase to 1-phase $\mathrm{SiC}$ matrix converter in terms of efficiency has been decreased very slightly by increasing switching frequency and temperature case of SiC devices. Among different SiC devices, SiC BJT amd JFET has 
shown higher efficiency in compare with SiC MOSFET in high temperature and switching frequency.

Analytical descriptions for calculating power losses in matrix converter are presented and then power losses of $\mathrm{Si}$ and $\mathrm{SiC}$ matrix converter are determined in various frequencies. It has been shown that high power $\mathrm{SiC}$ matrix converter would approximately have an efficiency that exceeds $96 \%$. It can be concluded that, the power electronic switches realized with $\mathrm{SiC}$ are respectable devices which will ensure the loss reduction and the improvement of power density in future.

\section{REFERENCES}

[1] T. R. McNutt, A. R. Hefner, H. A. Mantooth, D. Berning, and R. Sei-Hyung, "Silicon Carbide Power MOSFET Model and Parameter Extraction Sequence," Power Electronics, IEEE Transactions on, vol. 22, pp. 353-363, 2007.

[2] T. Funaki, J. C. Balda, J. Junghans, A. S. Kashyap, H. A. Mantooth, F. Barlow, T. Kimoto, and T. Hikihara, "Power Conversion With SiC Devices at Extremely High Ambient Temperatures," Power Electronics, IEEE Transactions on, vol. 22, pp. 1321-1329, 2007.

[3] R. A. Wood and T. E. Salem, "Evaluation of a 1200-V, 800-A All-SiC Dual Module," Power Electronics, IEEE Transactions on, vol. 26, pp. 2504-2511, 2011.

[4] J. Biela, M. Schweizer, S. Waffler, and J. W. Kolar, "SiC versus Si-Evaluation of Potentials for Performance Improvement of Inverter and DC-DC Converter Systems by SiC Power Semiconductors," Industrial Electronics, IEEE Transactions on, vol. 58, pp. 2872-2882, 2011.

[5] C. J. Cass, R. Burgos, F. Wang, and D. Boroyevich, "Improved charge control with adjustable input power factor and optimized switching pattern for a $150 \mathrm{kHz}$ three-phase buck rectifier," in Applied Power Electronics Conference and Exposition, 2008. APEC 2008. Twenty-Third Annual IEEE, 2008, pp. 1200-1206.

[6] L. Rixin, F. Wang, N. Puqi, Z. Di, J. Dong, R. Burgos, D. Boroyevich, K. J. Karimi, and V. D. Immanuel, "Development of a $10 \mathrm{~kW}$ high power density three-phase ac-dc-ac converter using SiC devices," in Power Electronics and Applications, 2009. EPE '09. 13th European Conference on, 2009, pp. 1-12.

[7] T. Friedli, S. D. Round, and J. W. Kolar, "A $100 \mathrm{kHz}$ SiC Sparse Matrix Converter," in Power Electronics Specialists Conference, 2007. PESC 2007. IEEE, 2007, pp. 2148-2154.

[8] S. Safari, A. Castellazzi, and P. Wheeler, "Evaluation of normally-off SiC JFET for a high power density matrix converter," in Power Electronics and Motion Control Conference (EPE/PEMC), 2012 15th International, 2012, pp. DS1a.9-1DS1a.9-7.

[9] S. Safari, A. Castellazzi, and P. Wheeler, "Evaluation of SiC power devices for a high power density matrix converter," in Energy Conversion Congress and Exposition (ECCE), 2012 IEEE, 2012, pp. 3934-3941.

[10] P. W. Wheeler, J. Rodriguez, J. C. Clare, L. Empringham, and A. Weinstein, "Matrix converters: a technology review," Industrial Electronics, IEEE Transactions on, vol. 49, pp. 276-288, 2002.

[11] B. Wrzecionko, S. Kach, D. Bortis, J. Biela, and J. W. Kolar, "Novel AC coupled gate driver for ultra fast switching of normally-off SiC JFETs," in IECON 2010 - 36th Annual Conference on IEEE Industrial Electronics Society, 2010, pp. 605612.

[12] X. Xu, A. Q. Huang, Y. Gao, A. Agarwal, S. Krishnaswami, S.-H. Ryu, and X. Huang, "Performance Evaluation of SiC MOSFET/BJT/Schottky Diode in A 1MHz Single Phase PFC," in Applied Power Electronics Conference, APEC 2007 Twenty Second Annual IEEE, 2007, pp. 1268-1272.

[13] R. J. Callanan, A. Agarwal, A. Burk, M. Das, B. Hull, F. Husna, A. Powell, J. Richmond, R. Sei-Hyung, and Z. Qingchun, "Recent progress in SiC DMOSFETs and JBS diodes at Cree," in Industrial Electronics, 2008. IECON 2008. 34th Annual Conference of IEEE, 2008, pp. 2885-2890.

[14] B. Buono, R. Ghandi, M. Domeij, B. G. Malm, C. M. Zetterling, and M. Ostling, "Modeling and Characterization of Current Gain Versus Temperature in 4H-SiC Power BJTs," Electron Devices, IEEE Transactions on, vol. 57, pp. 704-711, 
2010.

[15] S. Waffler, S. D. Round, and J. W. Kolar, "High temperature $\left(>>200^{\circ} \mathrm{C}\right)$ isolated gate drive topologies for Silicon Carbide (SiC) JFET," in Industrial Electronics, 2008. IECON 2008. 34th Annual Conference of IEEE, 2008, pp. 2867-2872.

[16] R. Burgos, C. Zheng, D. Boroyevich, and F. Wang, "Design considerations of a fast $0 \Omega$; gate-drive circuit for $1.2 \mathrm{kV}$ SiC JFET devices in phase-leg configuration," in Energy Conversion Congress and Exposition, 2009. ECCE 2009. IEEE, 2009, pp. 2293-2300.

[17] D. Domes, R. Werner, W. Hofmann, K. Domes, and S. Kraub, "A New, Universal and Fast Switching Gate-DriveConcept for SiC-JFETs based on Current Source Principle," in Power Electronics Specialists Conference, 2006. PESC '06. 37th IEEE, 2006, pp. 1-6.

[18] K. Mino, S. Herold, and J. W. Kolar, "A gate drive circuit for silicon carbide JFET," in Industrial Electronics Society, 2003. IECON '03. The 29th Annual Conference of the IEEE, 2003, pp. 1162-1166 Vol.2.

[19] I. Abuishmais, S. Basu, and T. M. Undeland, "On understanding and driving SiC power JFETs," in Applied Power Electronics Conference and Exposition (APEC), 2011 Twenty-Sixth Annual IEEE, 2011, pp. 1071-1075.

[20] B. Wrzecionko, D. Bortis, J. Biela, and J. Kolar, "Novel AC Coupled Gate Driver for Ultra Fast Switching of Normally-Off SiC JFETs," Power Electronics, IEEE Transactions on, vol. PP, pp. 1-1, 2011.

[21] I. SemiSouth Laboratories, "Two-Stage Opto Coupled Gate DriverDemo Board, ," SemiSouth Laboratories, Inc., 201Research Boulevard, Starkville, MS 39759, USA, Feb, 2010.

[22] J. Rabkowski, D. Peftitsis, H.-P. Nee, and M. Zdanowski, "A simple high-performance low-loss current-source driver for SiC bipolar transistors," in Power Electronics and Motion Control Conference (IPEMC), 2012 7th International, 2012, pp. $222-228$

[23] J. Rabkowski, G. Tolstoy, D. Peftitsis, and H. Nee, "Low-Loss High-Performance Base-Drive Unit for SiC BJTs," Power Electronics, IEEE Transactions on, vol. 27, pp. 2633-2643, 2012.

[24] B. Wang and G. Venkataramanan, "Analytical Modeling of Semiconductor Losses in Matrix Converters," in Power Electronics and Motion Control Conference, 2006. IPEMC 2006. CES/IEEE 5th International, 2006, pp. 1-8.

[25] K. Jun-Koo, H. Hara, E. Yamamoto, and E. Watanabe, "Analysis and evaluation of bi-directional power switch losses for matrix converter drive," in Industry Applications Conference, 2002. 37th IAS Annual Meeting. Conference Record of the, 2002, pp. 438-443 vol.1.

[26] F. Schafmeister, S. Herold, and J. W. Kolar, "Evaluation of $1200 \mathrm{~V}-S i-I G B T s$ and $1300 \mathrm{~V}-S i C-J F E T s$ for application in three-phase very sparse matrix AC-AC converter systems," in Applied Power Electronics Conference and Exposition, 2003. APEC '03. Eighteenth Annual IEEE, 2003, pp. 241-255 vol.1.

[27] M. Jussila and H. Tuusa, "Semiconductor Power Loss Comparison of Space-Vector Modulated Direct and Indirect Matrix Converter," in Power Conversion Conference - Nagoya, 2007. PCC '07, 2007, pp. 831-838. 